\title{
ENTROPY IN REGIONAL ANALYSIS
}

\author{
Teresa CZyż, Jan Hauke \\ Institute of Socio-Economic Geography and Spatial Management, \\ Adam Mickiewicz University, Poznań, Poland
}

Manuscript received: July 9, 2015

Revised version: October 6, 2015

Czyż T., Hauke J., 2015. Entropy in regional analysis. Quaestiones Geographicae 34(4), Bogucki Wydawnictwo Naukowe, Poznań, pp. 69-78, 5 tables, 5 figs. DOI 10.1515/quageo-2015-0037, ISSN 0137-477X.

AвSTRACT: Entropy has been proposed as a significant tool for an analysis of spatial differences. Using Semple and Gauthier's (1972) transformation of the Shannon entropy statistic into an entropy measure of inequality and their algorithm, an estimation is made of changes in regional inequality in Poland over the years 2005-2012. The inequality is decomposed into total, inter- and intra-regional types, and an analysis is made of relations holding between them.

KEY WORDS: entropy measure of inequality, decomposition of regional inequalities, changes in regional inequality pattern, Poland

Teresa Czyż, Jan Hauke, Institute of Socio-Economic Geography and Spatial Management, Adam Mickiewicz University, ul.Dzięgielowa 27,61-680 Poznań, Poland; e-mail: tczyz@amu.edu.pl, jhauke@amu.edu.pl

\section{Introduction}

What pose a problem for socio-economic development today in geographical terms are persistent, or even deepening, spatial differences found in a regional approach. Regional inequality is not conducive to development, and even hampers it (Ezcurra 2007). In the European Union states, including Poland, the chief goal of regional policy is to achieve internal economic and social cohesion by reducing regional inequality.

As follows from the literature on the subject, regional policy measures taken so far have not produced the expected results in reducing inter-regional differences within states. Hence regional policy has been modified. Apart from changes made in the activistic model of regional policy, empirical-diagnostic and methodological types of study of regional differences are conducted. In the methodological stream of the research, several sophisticated statistical methods have been proposed as ones offering new cognitive possibilities.

A survey of the research conducted so far shows that the basic statistical method of examining regional differences is an analysis of variance. It is also employed in an analysis of o convergence when comparing the scale of regional differences in a time series (Czyż, Hauke 2011). However, when considering the analysis of variance in terms of its assumptions, one might wonder whether this method yields a picture of regional differences valuable in cognitive terms, adequate to reality. Semple and Gauthier (1972: 170) draw attention to its weakness, namely its limitation in treating large deviations in income levels: "As it involves the squaring of income differentials, the analysis of variance may be highly sensitive to the few extreme deviations that are so common in development problems". Medvedkov (1969: 17) emphasises that "In many aspects entropy gives a more consistent approach to such problems than the classical analysis of variance 
and correlation. When applying entropy for information analysis one is not limited by the assumptions that variables influence each other according to linear laws". And he adds: "the concept of entropy acts as catalyst for better insight into complex relationships".

This article follows the cognitive stream of regional studies. It seeks to present entropy as a tool for an analysis of regional disparities, a tool that has not found much application in geographical research so far. It will be presented in a complementary approach that combines its mathematical-structural aspect with its empirical interpretation when examining inequality in Poland.

\section{The nature of entropy}

Entropy is a measure of the level of uncertainty in the probability distribution of random variables. This notion first appeared in thermodynamics, but has since found application in many fields of science. It was introduced to information theory by Shannon (1948). In defining and measuring entropy, use has been made of many forms of mathematical functions (Haynes et al. 1980). Their application has led to developing the concept of entropy in a variety of research contexts.

In spatial analysis the notion of entropy has been applied since as early as the 1960s. Berry and Schwind (1969: 5) justify the use of entropy and information in spatial analysis in the following words: "Increasingly persuasive arguments are being advanced that many spatial regularities result from purely random processes, that is, that they represent most probable steady-states. These arguments continue that deviations from such regularities should therefore be worthy of more attention than the regularities themselves, because it is the deviations that reveal underlying organisation and order. Information theory provides the means for formalizing these ideas. The statistically most probable state is equated with maximum entropy".

In geography, entropy is used as a measure of the spatial order, or uniformity, of an empirical system examined. Maximum entropy means maximum disorder and only slight internal diversity in this system: "When a system is completely ordered, it has minimum entropy, there is no uncertainty about its structure and it has no variety" (Batty 2010: 397).

The scholar regarded as the forerunner of the use of the concept of entropy in human geography is Wilson $(1967,1970)$, the creator of entropy-based models of spatial interaction. Among the first works in the field of geographical entropy are also those on entropy in settlement pattern analysis (Medvedkov 1966, 1969), in migrant flows (Berry, Schwind 1969), as an index of industrial concentration (Horowitz 1970), in trends in industrial dispersion (Griffin, Semple 1971), redundancy in inter-urban transport links (Semple, Wang 1971), in spatial-temporal trends in income inequalities (Semple, Gauthier 1972), and in the spatial distribution of the urban population (Batty 1974, 1975).

In Polish human geography, the first to use entropy as a research tool were Kostrubiec (1972) in his analysis of the configuration of a settlement network, as well as Chojnicki and Czyż (1976), who dealt with changes in the spatial concentration of industry in Poland.

Today entropy is part of the methodological output of world geography and finds application in ever new research fields. A significant role in the development of entropy-based methods has been played by Wilson's (2010) and Batty's (2010) studies. In Poland an upsurge of interest in the entropy method can be observed in spatial econometrics (Wędrowska 2010, 2012). In Polish socio-economic geography, the latest works on the use of entropy include a study of changes in the land-use pattern in metropolitan areas (Werner et al. 2014) and an analysis of the convergence of regional development (Kudrycka 2014).

In geographical studies on entropy the following research directions can be distinguished: (1) entropy as expected information used to verify hypotheses about the spatial distribution of phenomena, (2) entropy as a measure of dispersion of random phenomena, and (3) entropy-maximising models for the identification of the most probable spatial distribution and allocation of phenomena in a system.

It is worth noting that when analysing regional inequalities for a big enough number of regions and subregions, we have to consider spatial autocorrelation (SA). Griffith (1978) applies it in ANOVA; a positive SA tends to decrease intra-regional variance and to increase inter-re- 
gional variance. Li and Claramunt (2006) apply SA for entropy measures. In this case the measure is called spatial entropy rather than entropy. Here, however, we shall not deal with it.

\section{The general study problem}

In the research on entropy analysing geographical disparities various entropy statistics are employed, but the most popular is the Shannon entropy measure. Formulated in terms of information theory, it rests on the following assumption: "Any event with a very low probability that occurs gives us a great deal of information, whereas when an event with a high probability occurs, this is less of a surprise and gives us correspondingly less information. Information thus varies inversely with probability" (Batty 2010: 395).

The information obtained as a result of the appearance of an event is determined by a monotonic decreasing function with probability $p$ that takes the form: $\log 1 / p=-\log p$, which can also be treated as a measure of the uncertainty of the occurrence of the event.

For a series of events $x_{1}$ with probabilities $p_{i^{\prime}}, i$ $=1,2, \ldots, n$,

$$
0 \leq p\left(x_{i}\right) \leq 1, \sum_{\mathrm{i}=1}^{\mathrm{n}} p\left(x_{i}\right)=1,
$$

the measure of average information, that is, entropy $\mathrm{H}(\mathrm{x})$ as defined by Shannon (1948), is the expected value of this series, which can be written as:

$$
H(x)=-\sum_{\mathrm{i}=1}^{\mathrm{n}} p\left(x_{i}\right) \log p\left(x_{i}\right)
$$

or

$$
H(x)=\sum_{i=1}^{\mathrm{n}} p\left(x_{i}\right) \log _{2} \frac{1}{p\left(x_{i}\right)}
$$

The use of a logarithm to the base 2 means measurement of information in bits.

The Shannon entropy function has the following properties:

1. $H(x) \geq 0$, i.e. it is a non-negative quantity,
2. $\mathrm{H}(\mathrm{x})$ assumes the value of zero when $\mathrm{p}\left(\mathrm{x}_{\mathrm{i}}\right)=1$ for a specified $i$, which means the absence of uncertainty, and

3. $H(x)$ assumes the highest value equal to $\log _{2} n$ when all $\mathrm{p}\left(\mathrm{x}_{\mathrm{i}}\right)$ values are equal for $i=1,2, \ldots$, $n$. The maximum $\mathrm{H}(\mathrm{x})$ means total uncertainty (when it is impossible to say that one possibility is more probable than another), i.e. a disorder or total uniformity (in other words, a uniform distribution).

The $\mathrm{H}(\mathrm{x})$ entropy statistic as a measure of the uniformity of a distribution provides a basis for constructing an inequality measure $\mathrm{I}(\mathrm{x})$, or in the language of information theory, a measure of information differences. The inequality measure is useful in studies of spatial differences. It is governed by the equation:

$$
\begin{aligned}
I(x) & =H(x)_{\max }-H(x)=\log _{2} n-\sum_{i=1}^{n} p\left(x_{i}\right) \log _{2} \frac{1}{p\left(x_{i}\right)} \\
& =\sum_{i=1}^{n} p\left(x_{i}\right) \log _{2}\left[n p\left(x_{i}\right)\right]
\end{aligned}
$$

with

$$
0 \leq I(x) \leq \log _{2} n,
$$

where $\mathrm{I}(\mathrm{x})=0$ shows an absence of inequality (a uniform distribution), while $\mathrm{I}(\mathrm{x})=\log _{2} \mathrm{n}$ means a maximum non-uniformity in the occurrence of event $x$.

As far as we know, Semple and Gauthier (1972) as well as Gauthier and Semple (1974) were the first to employ the I(x) statistic in their research on regional inequalities in Brazil using an increase in per capita income $(x)$ as their index. To measure inter- and intra-regional inequalities in the development level and their relations, they adopted the following assumptions: (1) the studied country is subdivided into $R$ regions, $S_{1}, S_{2}, \ldots$ $S_{R^{\prime}}$ composed of subregions (states), (2) the total number of subregions is $n$, and (3) the number of subregions in $S_{r^{\prime}} r=1,2, \ldots, R$, is $n_{r^{\prime}}$ so that

$$
\sum_{r=1}^{R} n_{r}=n
$$

There are two stages in the research procedure employed by Semple and Gauthier (1972). In the first they apply the Shannon statistic in the form 


$$
H(x)=\sum_{r=1}^{R}\left[\sum_{i \in S_{r}} p\left(x_{i}\right) \log _{2} \frac{1}{p\left(x_{i}\right)}\right] .
$$

The expression in brackets can be expanded to:

$$
\begin{gathered}
\sum_{i \in S_{r}} p\left(x_{i}\right) \log _{2} \frac{1}{p\left(x_{i}\right)}= \\
p\left(x_{r}\right)\left\lfloor\sum_{i \in S_{r}}\left(\frac{p\left(x_{i}\right)}{p\left(x_{r}\right)} \log _{2} \frac{1}{\frac{p\left(x_{i}\right)}{p\left(x_{r}\right)}}\right)+\log _{2} \frac{1}{p\left(x_{r}\right)}\right\rfloor,
\end{gathered}
$$

where $\mathrm{p}\left(\mathrm{x}_{\mathrm{r}}\right)$ refers to $\mathrm{S}_{\mathrm{r}}$.

A combination of equations (3) and (4) yields an entropy equation taking the form:

$$
\begin{gathered}
H(x)=\sum_{r=1}^{R} p\left(x_{r}\right) \log _{2} \frac{1}{p\left(x_{r}\right)}+ \\
+\sum_{r=1}^{R} p\left(x_{r}\right)\left\lceil\sum_{i \in S_{r}} \frac{p\left(x_{i}\right)}{p\left(x_{r}\right)} \log _{2} \frac{1}{\frac{p\left(x_{i}\right)}{p\left(x_{r}\right)}}\right\rfloor .
\end{gathered}
$$

Equation (5) has two terms: the first is the entropy of variable (phenomenon) $x$ in the inter-regional system, the other is a weighted mean intra-regional entropy.

In the second stage, we get an entropy statistic of inequality $\mathrm{I}(\mathrm{x})$ on the basis of the following equation:

$$
\begin{gathered}
I(x)=\sum_{r=1}^{R} p\left(x_{r}\right) \log _{2} \frac{p\left(x_{r}\right)}{\frac{n_{r}}{n}}+ \\
+\sum_{r=1}^{R} p\left(x_{r}\right)\left\lfloor\sum_{i \in S_{r}} \frac{p\left(x_{i}\right)}{p\left(x_{r}\right)} \log _{2} \frac{\left.\frac{p\left(x_{i}\right)}{\frac{p\left(x_{r}\right)}{n_{r}}}\right\rfloor .}{}\right.
\end{gathered}
$$

The first term on the right-hand side of equation (6) deals with inter-regional inequality. It takes on the value of zero when $\mathrm{p}\left(\mathrm{x}_{\mathrm{r}}\right)=\mathrm{n}_{\mathrm{r}} / \mathrm{n}$. A special case occurs when the average $x$ per subregion is the same regardless of the region.

The second term on the right-hand side measures intra-regional inequality. It takes on the value of zero when $\mathrm{p}\left(\mathrm{x}_{\mathrm{i}}\right) / \mathrm{p}\left(\mathrm{x}_{\mathrm{r}}\right)=1 / \mathrm{n}_{\mathrm{r}}$. This occurs only when all $\mathrm{p}\left(\mathrm{x}_{\mathrm{i}}\right), \mathrm{i}=1,2, \ldots, n$, are equal within their respective regions.
In the case of spatial entropy, i.e., when SA is taken into account, the probabilities in formulae 1-6 should be reformulated by using the SA parameter or an eigenvector spatial filter (see, e.g., Batty 2010, Griffith 2003).

Entropy employed to study regional differences shows the following properties:

1. Entropy assumes that the spatial distribution of a phenomenon (e.g. income generated as an index of the economic power of regions) is the distribution of a random variable having a specified probability. Deviations from this distribution offer a significant insight into the hidden spatial order underlying the phenomenon.

2. Entropy can provide a basis for a measure of a non-uniform distribution of a phenomenon in the form of an inequality statistic.

3. The entropy statistic of inequality is a measure of inequality occurring in the entire regional system as determined by both intra-regional and inter-regional inequalities.

4. The mathematical structure of the entropy statistic of inequality makes it possible to distinguish two components of differences in the regional system: inter-regional inequalities and intra-regional inequalities, and to determine relations holding between them.

The decomposition of the inequality measure into an external part following from inter-regional inequalities, and an internal part determined on the basis of intra-regional inequalities, makes it possible to analyse inequality simultaneously in regions and their subregions. At this point it should be observed that the statistical measures employed only at the level of regions do not guarantee an estimate of actual inequality in a country's regional system. An analysis of inequality at the scale of a country should also embrace its intra-regional system because of wide differences in the internal development of individual regions.

The present study seeks to assess the cognitive value of the entropy method of examining regional inequalities or differences in Poland.

\section{Empirical analysis}

In the examination of regional differences in Poland in the years 2005-2012 using an entro- 


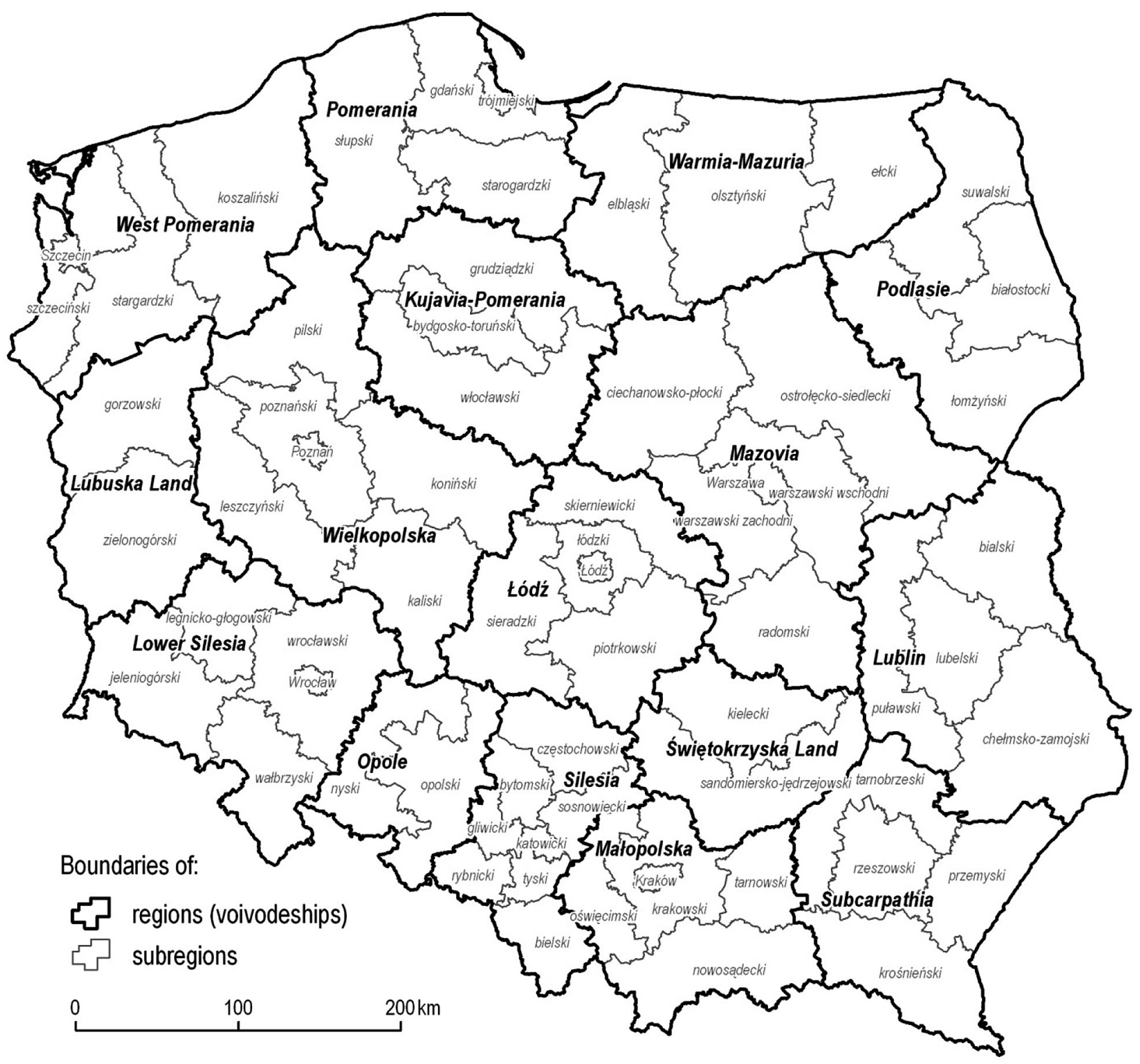

Fig. 1. Poland's division into regions and subregions

py measure of inequality, the set of basic units is composed of 66 subregions (fixed for Poland during the 2008-2014 period). They make up a total of 16 regions (voivodeships). The regions differ in the number of subregions (from 2 to 8 ) that form their internal structure (Fig. 1). In the EU statistical-territorial division, the regions correspond to NUTS $2^{1}$ units, and the subregions to NUTS 3 units.

The measures of the socio-economic development of regions and subregions include: (1) regional income and subregional income in the form of gross value added (GVA) in zlotys, or an

NUTS - The Nomenclature of Territorial Units for Statistics. absolute value, and (2) income weighted by the population number (per capita GVA), or a relative value. It is assumed that the income of a region or subregion determines its economic power, while income calculated per inhabitant reflects the level of its socio-economic development. In the years 2005-2012 Polish regions showed an increase in both, total income and its per capita value. Those two measures differ, however, in terms of stability over time. The probability of instability is greater in the case of relative dynamics than for absolute dynamics (Domański 2012: 194). In a region, an increase in per capita income is often combined with fluctuations in its demographic development, or even with a drop in its population number (the regions of Łódź, Silesia, 
Opole, and Świętokrzyska Land). The time series of data come from official statistics and concern the years 2005-2012. This study period offers the possibility of capturing changes in regional differences resulting from a new regional policy Poland has conducted since 2004, i.e. already as a member of the European Union. The area of the regions and subregions is not taken into account.

To identify differences in Poland's regional system, use was made of an entropy measure of inequality, I(x). Intra- and inter-regional inequalities were established in two variants: on the basis of income and on the basis of per capita income. The probability of the phenomenon (regional income or per capita income) occurring in a region equals

$$
x_{r} / \sum_{j=1}^{16} x_{j}
$$

and in a subregion

$$
x_{r i} / \sum_{j=1}^{n_{r}} x_{r j}
$$

where $\mathrm{x}_{\mathrm{r}}$ and $\mathrm{x}_{\mathrm{ri}}$ denote income $(x)$ in the $r$-th region and the $i$-th subregion of region $r$, respectively. The calculation of the entropy measure of inequality followed Semple and Gauthier's (1972) algorithm using equation (6), where $R=16$

Table 1. Poland's regions (voivodeships) and subregions.

\begin{tabular}{|l|c|}
\hline \multicolumn{1}{|c|}{ Regions } & Number of subregions \\
\hline Łódź & 5 \\
\hline Mazovia & 6 \\
\hline Małopolska & 5 \\
\hline Silesia & 8 \\
\hline Lublin & 4 \\
\hline Subcarpathia & 4 \\
\hline Podlasie & 3 \\
\hline Świętokrzyska Land & 2 \\
\hline Lubuska Land & 2 \\
\hline Wielkopolska & 6 \\
\hline West Pomerania & 4 \\
\hline Lower Silesia & 5 \\
\hline Opole & 2 \\
\hline Kujavia-Pomerania & 3 \\
\hline Pomerania & 4 \\
\hline Warmia-Mazuria & 3 \\
\hline Total & 66 \\
\hline
\end{tabular}

Table 2. Entropy measure of inequality on the basis of income generated $\mathrm{I}_{\mathrm{A}}(\mathrm{x})$, Poland, 2005-2012

\begin{tabular}{|c|c|c|c|}
\hline Year & $\begin{array}{c}\text { Total ine- } \\
\text { quality }\end{array}$ & $\begin{array}{c}\text { Intra-region- } \\
\text { al inequality }\end{array}$ & $\begin{array}{c}\text { Inter-region- } \\
\text { al inequality }\end{array}$ \\
\hline 2005 & 0.3686 & 0.2441 & 0.1246 \\
\hline 2006 & 0.3807 & 0.2498 & 0.1308 \\
\hline 2007 & 0.3855 & 0.2530 & 0.1325 \\
\hline 2008 & 0.3761 & 0.2458 & 0.1303 \\
\hline 2009 & 0.3809 & 0.2450 & 0.1359 \\
\hline 2010 & 0.3668 & 0.2336 & 0.1332 \\
\hline 2011 & 0.3607 & 0.2264 & 0.1343 \\
\hline 2012 & 0.3683 & 0.2309 & 0.1375 \\
\hline
\end{tabular}

denotes the number of regions, and $n_{r}$ the number of subregions in region $r$ (Table 1).

Measures of inequality were calculated for each year using equation (6). Tables 2 and 4 present the values of total (national) inequality in the set of 66 subregions, inter-regional inequality in the set of 16 regions (voivodeships), and intra-regional inequality in the set of 2 to 8 subregions. The inequality index $I_{A}(x)$ calculated on the basis of income as an absolute value was then examined in terms of a total (national) inequality index and decomposed into the indices of inter-regional inequality, $\mathrm{I}_{\mathrm{A}}(\mathrm{x})_{\text {inter }}$ and intra-regional inequality, $I_{A}(x)_{\text {intra }}$.

In the years 2005-2012, the $I_{A}(x)$ index assumed average values, ranging from 0.3607 to 0.3855 (with a theoretical maximum of 6.04 and a minimum of 0 ; Fig. 2). It displayed only slight variations over time. However, even with those slight fluctuations in its distribution over the study period one can observe that in the years 2005-2007, i.e. a period of Poland's accelerated

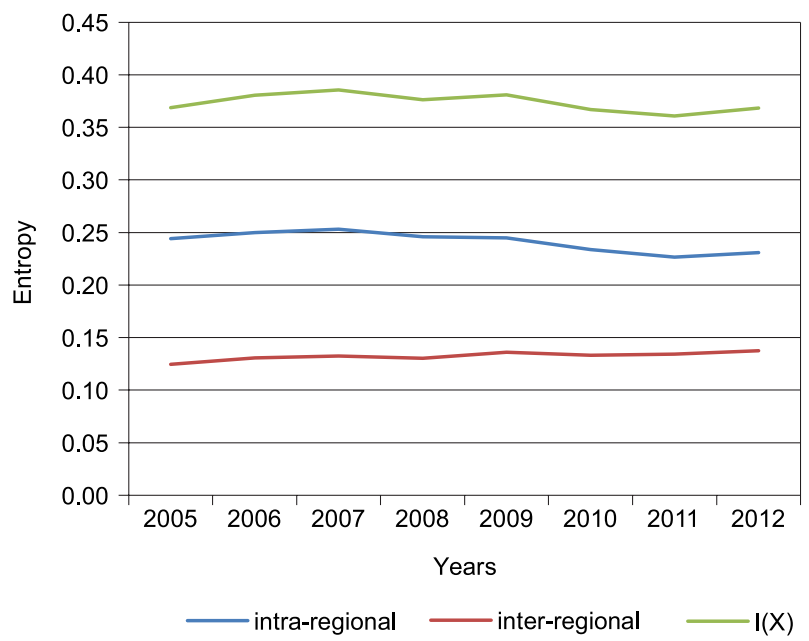

Fig. 2. Inequality in Poland on the scale of income generated in the years 2005-2012 on the basis of the entropy measure of inequality 
economic growth, there was a small increase in inequality; in the years 2008-2009, i.e. a period of a slow-down in the economy, first a decline (2008), then an increase (2009), while in the next years 2010-2012 inequality was practically at its 2005 level. Over the entire study period, the chief component of national inequality was intra-regional inequalities (Table 3), which accounted for $66.2 \%$ to $62.2 \%$ of total inequality, their proportion dwindling steadily. Inter-regional inequalities accounted for $33.8 \%$ to $37.4 \%$ of total inequality, their contribution being relatively small but growing. In the years 2005-2012 the total inequality curve shows greater similarity to that of intra-regional inequalities than to that of inter-regional inequalities (Fig. 2).

The decomposition of inequality is connected with a specified distribution of income probabilities in the regions and their subregions in the years 2005-2012. With probability assumed to be greater than 0.05 , the highest probability of income in the regions, and showing an upward tendency (0.2127-0.2187), was noted for Mazovia, next came Silesia (0.1331-0.1269) with a declining probability, followed by Wielkopolska

Table 3. Decomposition of total inequality $\mathrm{I}_{\mathrm{A}}(\mathrm{x})$ expressed in \%

\begin{tabular}{|c|c|c|}
\hline Year & $\begin{array}{c}\text { Intra-regional } \\
\text { inequality }\end{array}$ & $\begin{array}{c}\text { Inter-regional } \\
\text { inequality }\end{array}$ \\
\hline 2005 & 66.2 & 33.8 \\
\hline 2006 & 65.6 & 34.4 \\
\hline 2007 & 65.6 & 34.4 \\
\hline 2008 & 65.3 & 34.7 \\
\hline 2009 & 64.3 & 35.7 \\
\hline 2010 & 63.7 & 36.3 \\
\hline 2011 & 62.8 & 37.2 \\
\hline 2012 & 62.6 & 37.4 \\
\hline
\end{tabular}

Table 4. Entropy measure of inequality on the basis of per capita income $I_{C}(x)$, Poland, 2005-2012

\begin{tabular}{|c|c|c|c|}
\hline Year & $\begin{array}{c}\text { Total ine- } \\
\text { quality }\end{array}$ & $\begin{array}{c}\text { Intra-region- } \\
\text { al inequality }\end{array}$ & $\begin{array}{c}\text { Inter-region- } \\
\text { al inequality }\end{array}$ \\
\hline 2005 & 0.1360 & 0.0624 & 0.0736 \\
\hline 2006 & 0.1388 & 0.0653 & 0.0735 \\
\hline 2007 & 0.1416 & 0.0662 & 0.0754 \\
\hline 2008 & 0.1374 & 0.0634 & 0.0740 \\
\hline 2009 & 0.1359 & 0.0636 & 0.0723 \\
\hline 2010 & 0.1335 & 0.0634 & 0.0700 \\
\hline 2011 & 0.1291 & 0.0617 & 0.0674 \\
\hline 2012 & 0.1291 & 0.0624 & 0.0667 \\
\hline
\end{tabular}

(0.0946-0.0954), Lower Silesia (0.0781-0.0863), Małopolska (0.0733-0.0769) and Pomerania (0.0568-0.0581) with fluctuations in probability values, and Łódź (0.0623-0.0610) with a decreasing probability value. The regional probability values obtained are indicative of a significant effect, persisting over the study period, of those six regions with well-developed urban agglomerations on inter-regional inequality.

In the intra-regional system, the highest income probabilities can be found in subregions that constitute the cores of urban agglomerations or large cities performing the role of regional centres. Those urban subregions are greatly responsible for intra-regional contrasts. However, in the years 2005-2012 the probabilities assigned to them keep falling, while those in their neighbouring subregions tended to increase. For example, in Mazovia the income probability in the Warsaw subregion decreased from 0.6135 in 2005 to 0.5909 in 2012, while the probabilities in the neighbouring subregions of East Warsaw grew from 0.0730 to 0.0809 , and in West Warsaw, from 0.1027 to 0.1162 . It is worth noting that in a subregion peripheral to Mazovia, namely the Radom subregion, income probability dropped from 0.0573 to 0.0536 .

Over the study period, the total national inequality index calculated on the basis of per capita income (or income weighted by the population number), $\mathrm{I}_{\mathrm{C}}(\mathrm{x})$, assumed lower values than the $\mathrm{I}_{\mathrm{A}}(\mathrm{x})$ index, ranging from 0.1291 to 0.0416 (Table 4, Fig. 3). This means that the differences were less pronounced on the scale of income calcu-

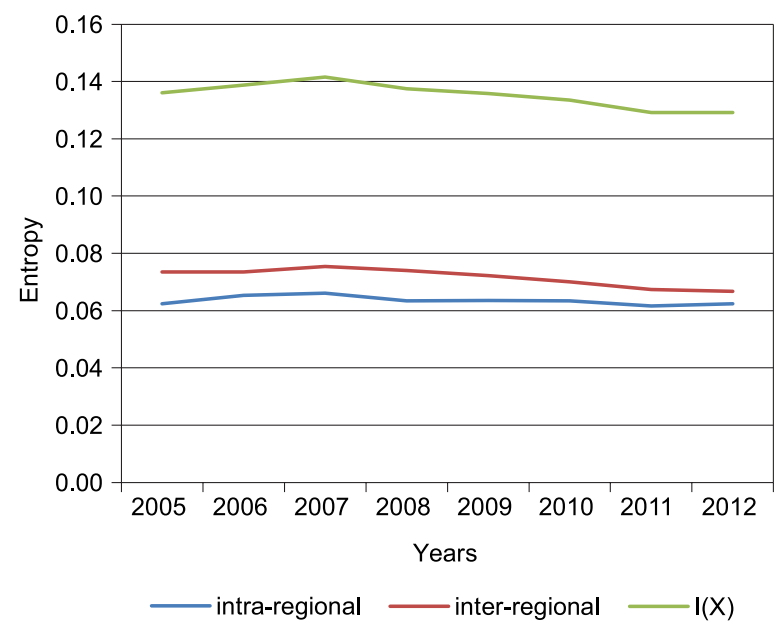

Fig. 3. Inequality in Poland on the scale of regional per capita income in the years 2005-2012 on the basis of the entropy measure of inequality 
Table 5. Decomposition of total inequality $\mathrm{I}_{\mathrm{C}}(\mathrm{x})$, expressed in \%

\begin{tabular}{|c|c|c|}
\hline Year & $\begin{array}{c}\text { Intra-regional } \\
\text { inequality }\end{array}$ & $\begin{array}{c}\text { Inter-regional } \\
\text { inequality }\end{array}$ \\
\hline 2005 & 45.9 & 54.1 \\
\hline 2006 & 47.0 & 53.0 \\
\hline 2007 & 46.7 & 53.3 \\
\hline 2008 & 46.1 & 53.9 \\
\hline 2009 & 46.8 & 53.2 \\
\hline 2010 & 47.5 & 52.5 \\
\hline 2011 & 47.8 & 52.2 \\
\hline 2012 & 48.3 & 51.7 \\
\hline
\end{tabular}

lated per inhabitant than on the scale of income generated. The curve of the $\mathrm{I}_{C}(\mathrm{x})$ index shows its increase from 0.1360 to 0.1416 in the years 20052007 , and then a systematic drop down to the value of 0.1291 in the years 2008-2012. When comparing the shapes of curves of $\mathrm{I}_{C}(\mathrm{x})$ and $\mathrm{I}_{\mathrm{A}}(\mathrm{x})$ over time, one can observe that in the latter subperiod there was a systematic drop in the index of inequality on the scale of per capita income accompanied by fluctuations in the index of inequality on the scale of income generated.

In the years 2005-2012, inter-regional inequalities $I_{C}(x)_{\text {inter }}$ showed a slight predominance over intra-regional inequalities $I_{C}(x)_{\text {intra }}$ in national inequality $I_{C}(x)$, but this predominance kept dwindling systematically over time. The proportion of inter-regional inequalities decreased from $54.1 \%$

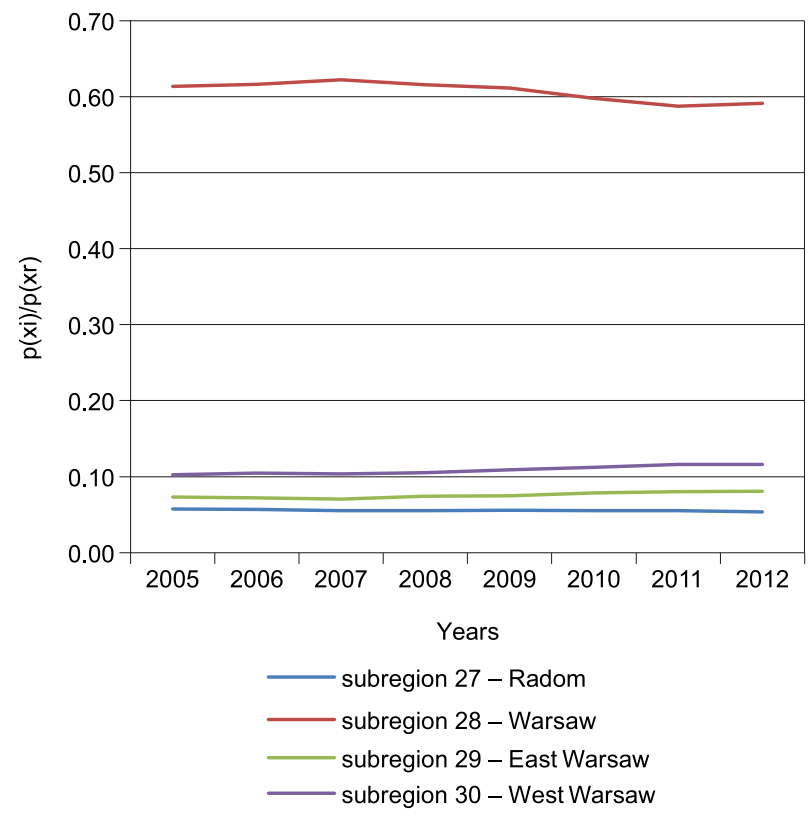

Fig. 4. Internal differences in Mazovia on the basis of the probability of income generated in the years 2005-2012 in 2005 to $51.7 \%$ in 2012 , while that of intra-regional inequalities grew from $45.9 \%$ in 2005 to $48.3 \%$ in 2012 (Table 5). Over the study period changes in the decomposition of inequality determined on the basis of per capita income were also connected with changes in the probability of weighted income in the regional and subregional systems.

In the system of regions, high probabilities of per capita income were recorded in Mazovia (0.1072-0.1095) and Łódź (0.0629-0.0643) - an increase with fluctuations; Silesia (0.0738-0.0729), Wielkopolska (0.0729-0.0731) and Pomerania (0.0671-0.0673) - with fluctuations; Małopolska (0.0584-0.0609) and Lower Silesia (0.0703-0.0729) - with an upward tendency; and West Pomerania (0.0626-0.0581) - with a downward tendency. In the internal system, there were wide differences in 2005 between subregions with maximum and minimum values of probability of per capita income in the following regions: Mazovia (Warsaw city, 0.3922; Ostrołęka-Siedlce subregion, 0.0988), Małopolska (Cracow city, 0.3693; Nowy Sącz subregion, 0.1398), Pomerania (Tri-City, 0.4046; Gdańsk subregion, 0.1834), West Pomerania (Szczecin city, 0.3609; Stargard subregion, 0.1784), Wielkopolska (Poznań city, 0.3147; Kalisz subregion, 0.1244), and Kujavia-Pomerania (Bydgoszcz-Torun subregion, 0.4435; Grudziądz subregion, 0.2674) (Fig. 5). In the successive years the

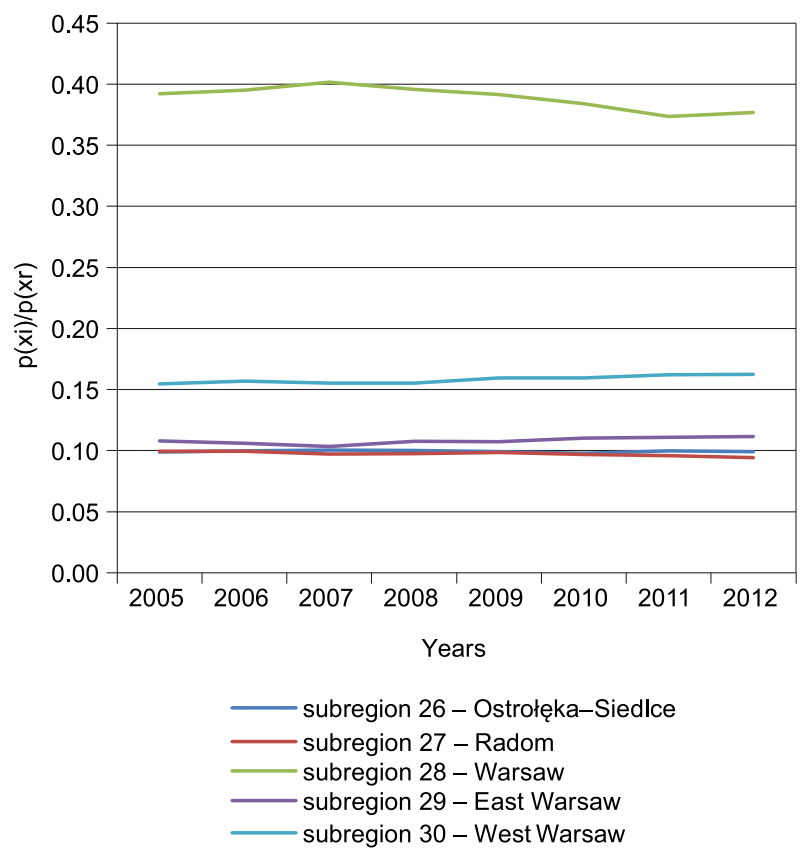

Fig. 5. Internal differences in Mazovia on the basis of the probability of per capita income in the years 2005-2012 
internal contrasts in those six regions persisted with only slight changes. The subregions of the remaining regions differed much less in terms of the probability values of per capita income.

An analysis of probability distributions within the regions shows that in the individual subregions the values of the probability of per capita income are much lower than those of the probability of income generated.

\section{Final conclusions}

The use of the entropy measure of inequality to analyse differences in the level of socio-economic development of Poland leads to the following conclusions:

1. National inequalities (in the system of 66 subregions) determined on the basis of the distribution of income generated are at an average level, and on the basis of per capita income, below the average.

2. In the years 2005-2012 intra-regional inequalities contributed a greater share than inter-regional ones to national inequality in terms of income generated.

3. The decomposition of national inequality determined in terms of per capita income shows the contribution of inter-regional inequalities to be slightly greater than that of intra-regional ones.

However, we should remember that the small number of subregions (2-8) limits the discussion of intra-regional distributions.

Thus, it can be stated that differences in Poland are wider when the index of income generated rather than that of per capita income is employed to reveal them. In the first case, there is a distinct prevalence of intra-regional inequalities in the structure of inequality, and when the other index is used, there is a slight predominance of inter-regional inequalities. Over time, however, those indices show different tendencies: on the scale of income generated, the share of intra-regional inequalities decreases and that of inter-regional ones grows, while on the scale of per capita income, the share of intra-regional inequalities stabilises after a period of fluctuations, and that of inter-regional ones decreases.

The above findings lead to the following empirical-diagnostic conclusions:
1. In the years 2005-2012, which include a slowdown period and a crisis in the socio-economic development of Poland, a significant role in the appearance of differences was played by intra-regional inequalities.

2. What affected the slight changes in total differences in Poland and in the decomposition of inequality were both changes in the spatial distribution of the country's economic potential (in terms of the index of income generated) and spatial changes in the level of socio-economic development (in terms of the index of per capita income).

3. The level of and relations between inter- and intra-regional inequalities in Poland are largely determined by the development rate of regions with urban agglomerations. Those regions are characterised by a rate of economic development above the national average and persisting internal contrasts, but with symptoms of their weakening brought about by the diffusion of development from the central city to the subregions of the suburban zone.

Finally, it should be concluded that in the years 2005-2012 there were no distinct systematic changes in the spatial distribution of the phenomenon examined and in regional inequalities, with the growth of income showing a permanent temporal upward tendency, even though its intensity differed at the scale of the country as well as in regions and their subregions. The temporal and spatial changes in inequality patterns were irregular (fluctuations) and showed a decline, an increase or stagnation in them. This kind of changes in regional inequality estimated for a short period of the trade cycle cannot provide a basis for the extrapolation of change in the country's spatial structure.

\section{References}

Batty M., 1974. Spatial entropy. Geographical Analysis 8: 1-32. Batty M., 1975. Urban density and entropy functions. Geographical Papers, 36. Department of Geography, University of Reading, England.

Batty M., 2010. Space, scale, and scaling in entropy maximizing. Geographical Analysis 42: 395-421.

Berry B.J.L., Schwind P.J., 1969. Information and entropy in migrant flows. Geographical Analysis 1: 5-14.

Chojnicki Z., Czyż T., 1976. Entropia jako miara koncentracji przemystu (Entropy as a measure of the concentration of industry). Sprawozdania nr 91 za 1973 r., Poznańskie Towarzystwo Przyjaciół Nauk, Poznań: 61-63. 
Czyż T., Hauke J., 2011. Evolution of regional disparities in Poland. Quaestiones Geographicae 30(2): 35-48.

Domański R., 2012. Ewolucyjna gospodarka przestrzenna (Evolutionary spatial management). Wydawnictwo Uniwersytetu Ekonomicznego w Poznaniu, Poznań.

Ezcurra R., 2007. Is income inequality harmful for regional growth? Evidence from the European Union. Urban Studies 44(10): 1953-1971.

Gauthier H.L., Semple R.K., 1974. Trends in regional inequalities in the Brazilian economy 1947-1966. In: Thoman R.S. (ed.), Methodology and case studies, vol. I. Proceedings of the Commission on Regional Aspects of Development of the IGU. Hayword, California, USA: 249-266.

Griffin J.M., Semple R.K., 1971. Spatial-temporal trends in industrial dispersion. Discussion Paper No. 23, Department of Geography, Ohio State University.

Griffith D.A., 1978. A spatially adjusted ANOVA model. Geographical Analysis 10: 296-301.

Griffith D.A., 2003. Spatial autocorrelation and spatial filtering: Gaining understanding through theory and scientific visualization. Springer, Berlin - New York.

Haynes K.E., Phillips F.Y., Mohrfeld J.W., 1980. The entropies: Some roots of ambiguity. Socio-Economic Planning Sciences 14: 137-145.

Horowitz I., 1970. Employment concentration in the Common Market: An entropy approach. Journal of the Royal Statistical Society 135(3), Series A: 463-479.

Kostrubiec B., 1972. Analiza zjawiska koncentracji w sieci osadniczej (Analysis of the phenomenon of concentration in a settlement network). Instytut Geografii PAN, Prace Geograficzne 93, Wrocław.

Kudrycka J., 2014. A convergence analysis of regional development in Poland. III Scientific Conference on Spatial Econometrics and Regional Economic Analysis, Lódź, June 9-10, 2014
Li X., Claramunt C., 2006. A spatial entropy-based decision tree for classification of geographical information. Transactions in GIS 10: 451-467.

Medvedkov Y.V., 1966. The concept of entropy in settlement pattern analysis. Regional Science Association Papers XVII, Vienna Congress: 165-168.

Medvedkov Y.V., 1969. Entropy: An assessment of potentialities in geography. Session of the IGU Commission on Quantitative Methods, London.

Semple R.K., Wang L.H., 1971. A geographical analysis of changing redundancy in inter-urban transportation links. Geografiska Annaler 3, Series 53B: 1-5.

Semple R.K., Gauthier H.L. 1972. Spatial-temporal trends in income inequalities in Brazil. Geographical Analysis 2: 189-179.

Shannon C.E., 1948. A mathematical theory of communication. Bell System Technical Journal 27: 379-423, 623-656.

Werner P., Korcelli P., Kozubek E., 2014. Population potential as a modulator of land use changes in Poland's metropolitan areas. Quaestiones Geographicae 33(2): 37-50.

Wędrowska E., 2010. Wykorzystanie entropii Shannona i jej uogólnień do badania rozkładu prawdopodobieństwa zmiennej losowej dyskretnej (Use of the Shannon entropy and its generalisations in a study of the probability distribution of a discrete random variable). Przeglad Statystyczny LVII (4): 39-53.

Wędrowska E., 2012. Miary entropii $i$ dywergencji w analizie struktur (Measures of entropy and divergence in an analysis of structures). Wydawnictwo UWM, Olsztyn.

Wilson A.G., 1967. A statistical theory of spatial distribution models. Transport Research 1: 253-269.

Wilson A.G., 1970. Entropy in urban and regional modelling. Pion Press, London.

Wilson A.G., 2010. Entropy in urban and regional modelling: Retrospect and prospect. Geographical Analysis 42: 364-394. 